\title{
An in situ monitoring system for the study of environmental influences on durability and the destructive process of building materials and structures
}

\author{
Z. Pavlík, J. Fořt \& R. Černý \\ Department of Materials Engineering and Chemistry, Faculty of Civil \\ Engineering, Czech Technical University in Prague, Czech Republic
}

\begin{abstract}
An in situ monitoring system for the study of environmental influences on durability, destructive process and hygrothermal performance of building materials and structures is designed. The experience gained during the laboratory and semi-scale critical experiments is utilized, as for the test probes and data acquisition systems. Taking into account that testing on real structures is done at their common operation conditions, the extent of testing cannot be as wide as in the laboratory conditions. On this account, a lower number of field variables is monitored and the data acquisition systems are simpler than in laboratory and semi-scale conditions. The designed in situ monitoring system is applied for a typical building commonly constructed on the territory of Central Europe and the results of the initial part of the monitoring process are presented.

Keywords: in situ monitoring, relative humidity, temperature, hygrothermal performance.
\end{abstract}

\section{Introduction}

Transport and accumulation of heat, moisture, chemical substances and momentum are phenomena which affect the building materials and structures over their whole lifetime period. Therefore, their experimental and computational analyses belong to the most often studied subjects. However, these processes are mostly investigated without taking into account any time factor at all, or, in a better case, such factors are oversimplified. For material or 
structural deterioration analyses this kind of treatment is rather insufficient because the phenomena under consideration are not only time dependent but also cumulative.

Assessment of hygrothermal and mechanical performance of buildings or their particular structures can be basically done in three different ways. The first possibility represents application of computational modelling. Mathematical models of heat and moisture transport related to the mechanical effects are very effective tools in predicting building behaviour and are often used in building envelope design at present. However, any model can provide reliable information only in the case that the quality of input data is sufficient [1]. This is not always true because the standard lists of thermal, hygric, and mechanical parameters are usually far for complete. They also often do not include the dependencies of basic parameters on field variables of heat and moisture transport [2]. In addition, the models always work with some parameters, which are not known explicitly (for instance hygric and thermal interface and surface resistances) and often neglect some effects (e.g. the Soret and Dufour effect, relation of moisture content variation to the length and volumetric changes, etc., which can be possibly important under specific conditions. Therefore, the models have to be tested very thoroughly before they can be applied to serious service life and durability prediction analyses [3].

Experimental methods of testing the hygrothermal and mechanical performance of building envelopes are certainly more reliable, but they suffer other types of problems. Looking at experimental methods of building structures testing, two approaches can be distinguished. There can be applied so called semi-scale experiments that are usually done at laboratory and fragment of the building structure is exposed to the simulated harmful climatic conditions. Since these experiments maintain their laboratory character, precise laboratory methods for measurement of field variables as moisture [4], relative humidity, temperature, deformation and mechanical stresses can be applied. Also the expenses of performed tests can be kept considerably lower compared to a real test house and in-situ measurement [5]. The semi-scale experiments find use especially in design and testing of new multilayered building structures and in testing of smaller fragments of existing structures. They are also used in combination with computation modelling and for validation of computational models. Comparing real data with simulation data helps to find possible deviations of in situ test due, for example, to small deviations in measuring instrumentation, as the limits or fluctuations in the software simulation results [6].

From a practical point of view, experimental monitoring of building performance in situ provides the most reliable information on its behaviour at real climatic conditions and is highly popular in building practice and research. It also represents final and decisive step in testing of new materials and technologies applied in buildings. Among the in situ measurement, test house monitoring represents specific category of research. Although the measuring methods applied for in situ measurement are less precise and reliable compared to laboratory advanced methods, they give sufficient information on buildings 
performance. The popularity of in situ tests can be demonstrated by many examples presented in the scientific literature. In this paper, only several of them will be introduced. Kijewski-Correa and Kochly [7] monitored the wind-induced response of tall buildings using GPS. Full-scale monitoring is also an important tool to evaluate the performance of dynamically sensitive structures and assure that the design assumptions and methodologies used to predict their responses yield accelerations that are consistent with in situ behaviours [8]. Omenzetter et al. [9] performed long-term monitoring of dynamical responses of innovative multistory timber building to forced vibration. Experimental testing of thermal insulation function of vacuum insulation panels in a flat room construction studied (Brunner and Simmler [10]). Here, monitoring data from a terrace construction over more than 3 years are reported. The results are compared with laboratory aging data at constant conditions by linear and Arrhenius weighting of the dynamic boundary conditions. Based on satisfactory agreement, a similar approach is applied for the prediction of the thermal performance after an installation time for 25 years, the common time used for building design regarding energy performance. Effect of wind on the transmission heat loss in duo-pitched insulated roofs investigated (Janssens and Hens [11]). Swinton et al. [12] evaluated in situ performance of spray polyurethane foam in the exterior insulation basement system. They concluded that the key performance factors of the $76 \mathrm{~mm}$ thick spray polyurethane foam specimens sprayed on the exterior surfaces of the concrete basement wall all remained at a very good level.

Energy consumption worldwide is increasing due to the increasing population, migration to large cities and improvement in standard of living. With worldwide rising of energy consumption and energy cost in the building sector, there is a press to reduce energy consumption for buildings operation and to use renewable energy. Energy consumption for heating and cooling purposes in buildings can be reduced by appropriate building envelope components in terms of thermo-physical-optical and dimensional properties.

Because of the evident need of energy saving for operation of buildings, we focused in this paper on hygrothermal monitoring of administrative building typically built in the Czech Republic in 1980s and 1990s. Such types of building usually suffer from high heat losses or gains through the envelope systems as well as from moisture related durability problems of inbuilt materials. For that purposes, simple in situ monitoring system was designed, in order to monitor the building envelope behaviour at specific climatic conditions of Prague, Czech Republic.

\section{Experimental}

\subsection{Investigated building}

The monitored building was built in 1980s. It is typical reinforced concrete column structure. The exterior surface is constructed from the hung facade slabs formed of steel frames, aluminous window frames, glass, and insulation boards. 
Part of the envelope is built from cavity brick blocks and on the surface is provided by cement-lime plaster. The building is located in the north-west suburb part of Prague, capital of the Czech Republic.

\subsection{Applied sensors and their placing}

The monitoring of hygrothermal building performance was done for the part of the envelope formed by cavity brick blocks and exterior and interior plasters. This part of building facade is considered to be the main cause of heat losses of the building. Here, also the materials durability problems are expected.

In the tested structure, continuous monitoring of relative humidity and temperature was done. For that purpose, the combined mini-sensors produced by Ahlborn, Germany, were used. Used capacitance relative humidity sensors are applicable in the range of humidities of $5-98 \%$ with the accuracy within $\pm 2 \%$, resistive temperature sensors had the accuracy of $\pm 0.4^{\circ} \mathrm{C}$ in the temperature range of -20 to $0^{\circ} \mathrm{C}$ and $\pm 0.1^{\circ} \mathrm{C}$ in the range of $0-70^{\circ} \mathrm{C}$. The particular sensors were connected with measuring unit that was controlled by computer. The data were continuously collected, whereas the experiment was controlled by remote computer station.

Sensor placing and orientation of the tested building is given in Figures 1-3. In total, 16 measuring channels were installed.

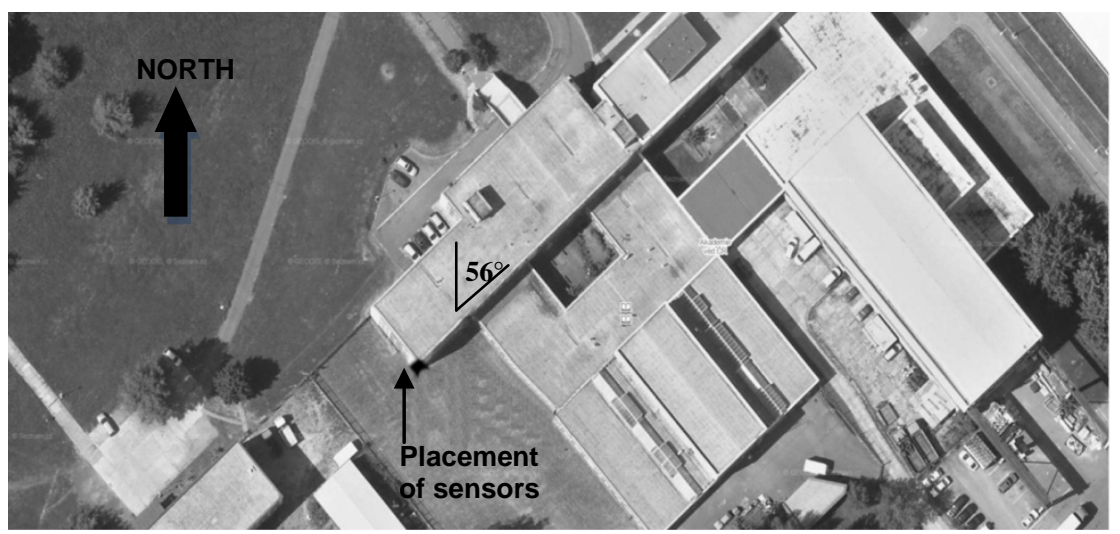

Figure 1: $\quad$ Orientation of monitored building and sensor placing.

\section{Results and discussion}

Measured relative humidity and temperature profiles plotted across the studied envelope are given in Figures 4-7. Here, data from the beginning of the experiment in April 2012 until December 2012 are presented. 


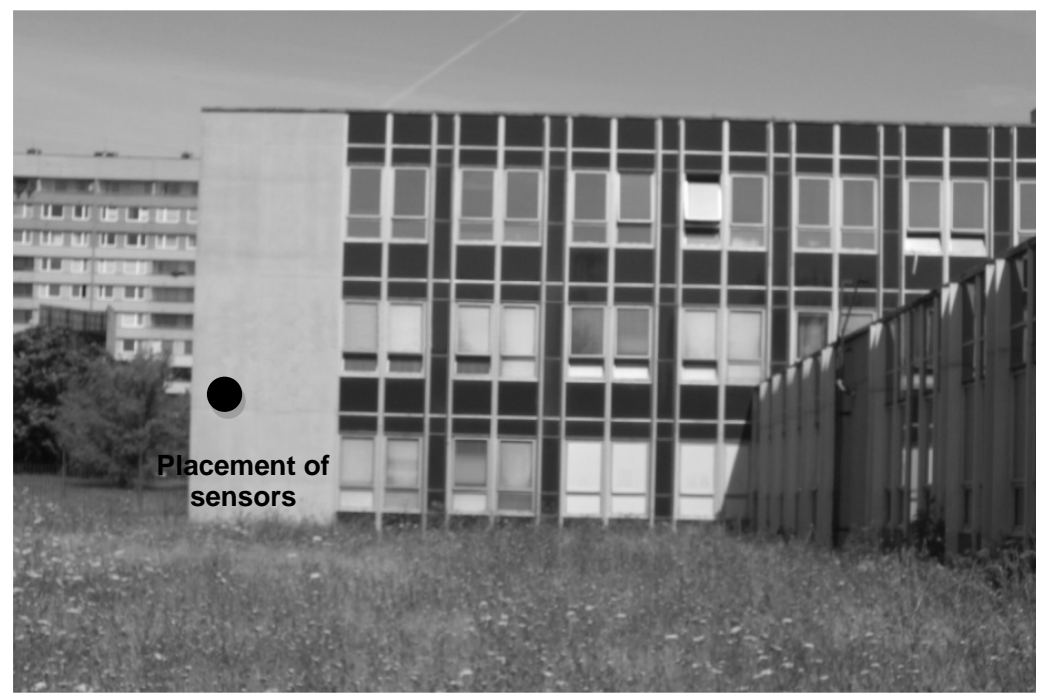

Figure 2: $\quad$ View of the studied building and sensor placing.

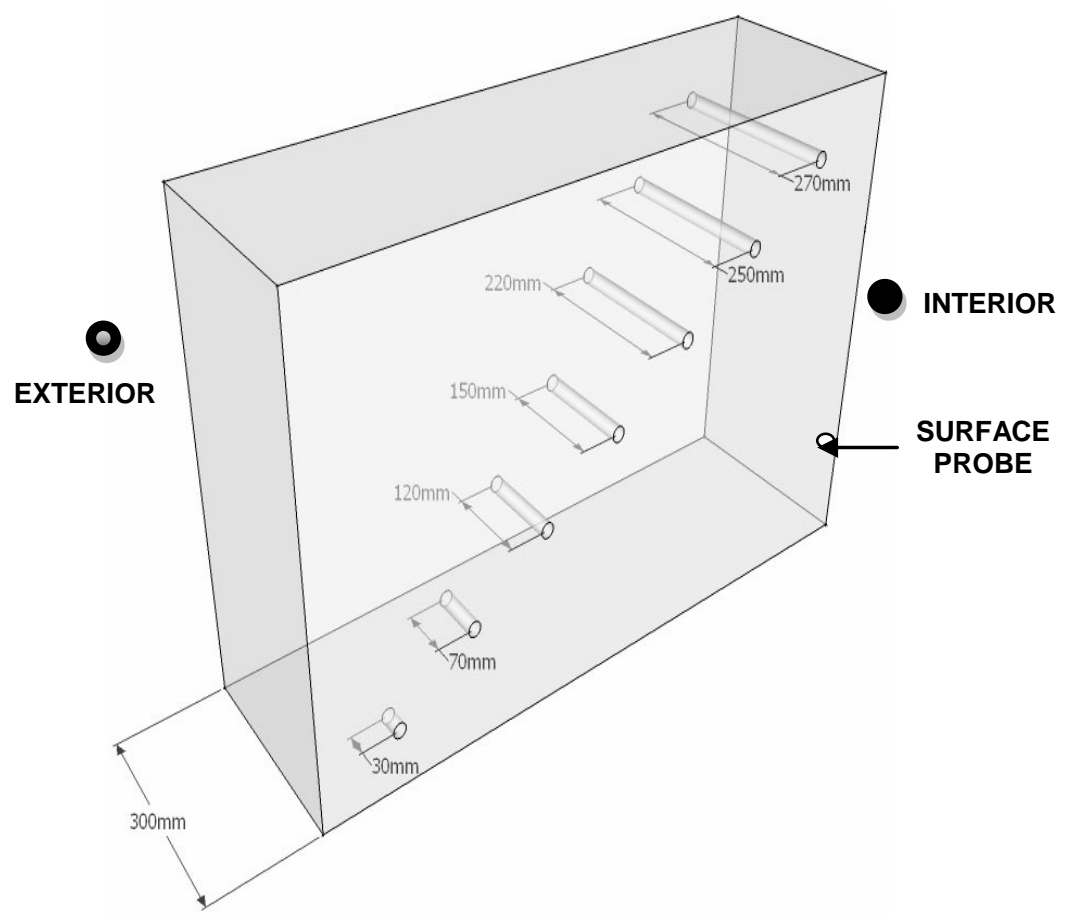

Figure 3: Schematic view of sensor installation. 
292 Computational Methods and Experimental Measurements XVI

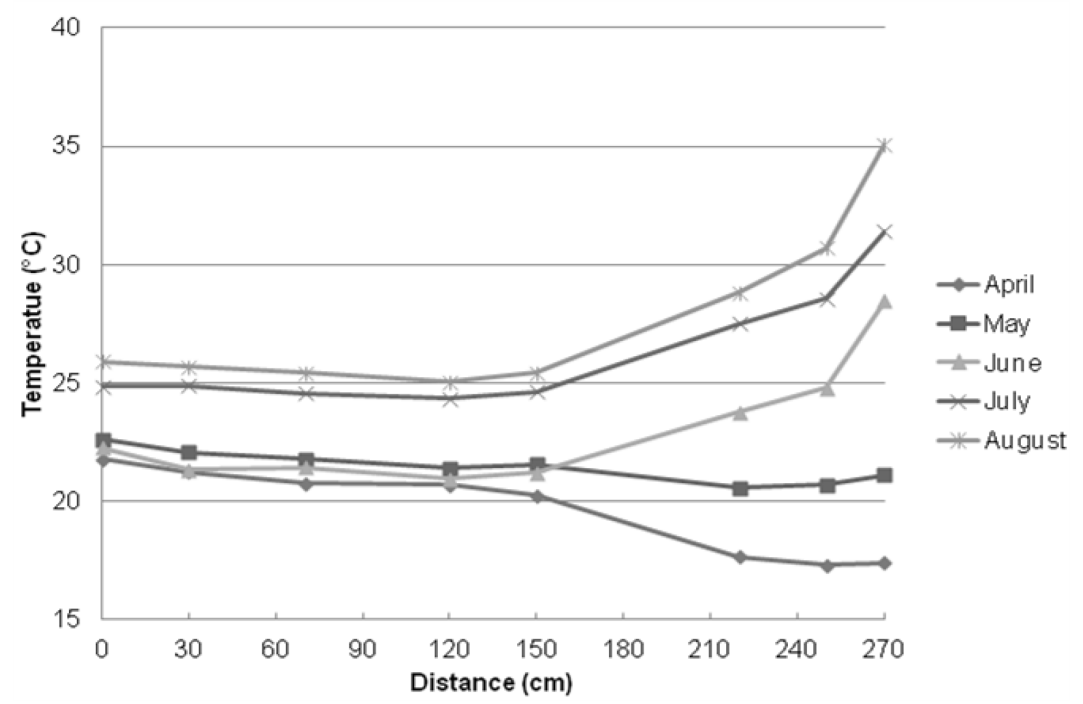

Figure 4: Temperature profiles measured during the spring and summer of 2012.

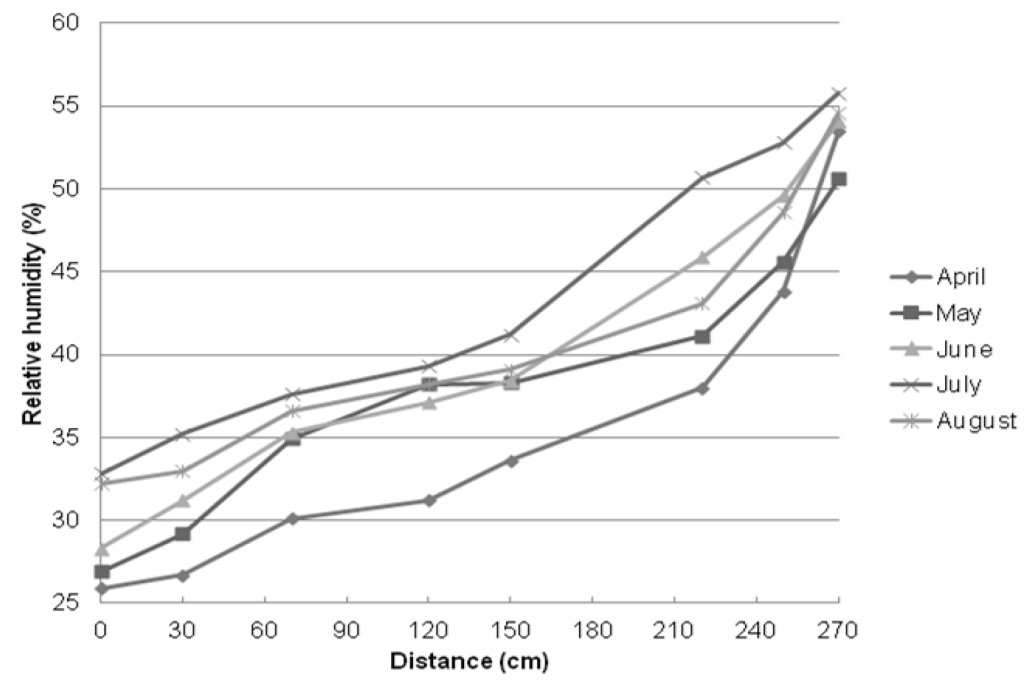

Figure 5: Relative humidity measured during the spring and summer of 2012. 


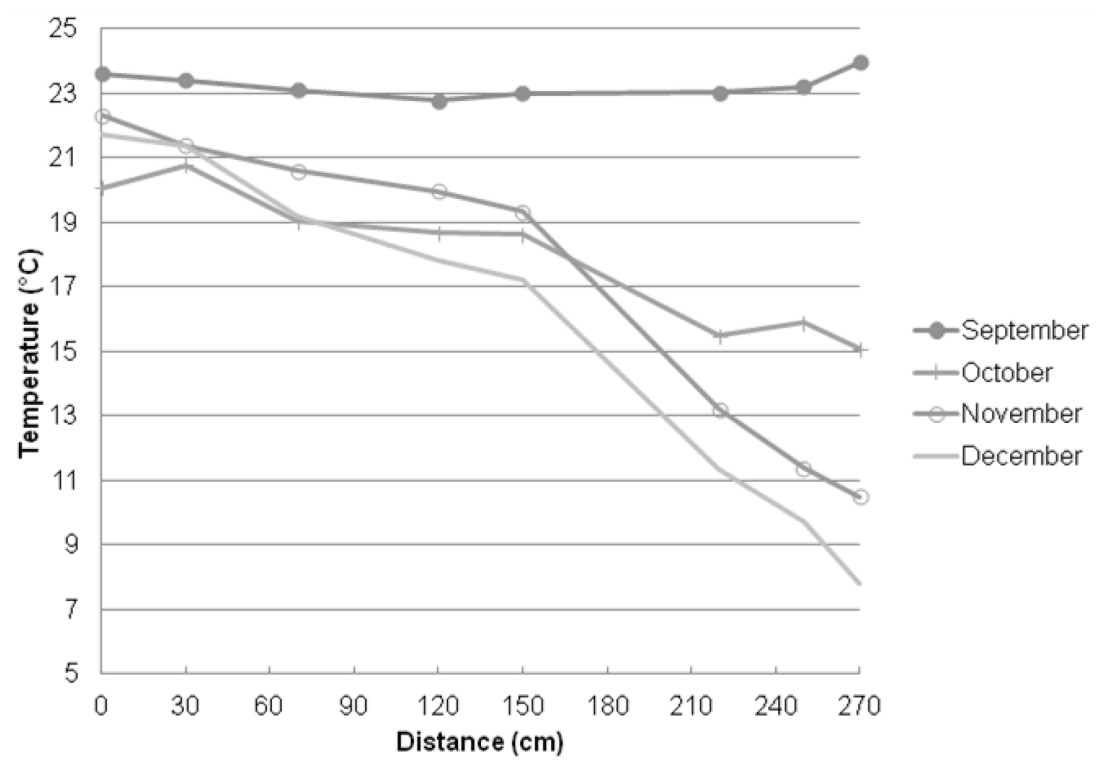

Figure 6: Temperature profiles measured during the autumn and winter of 2012.

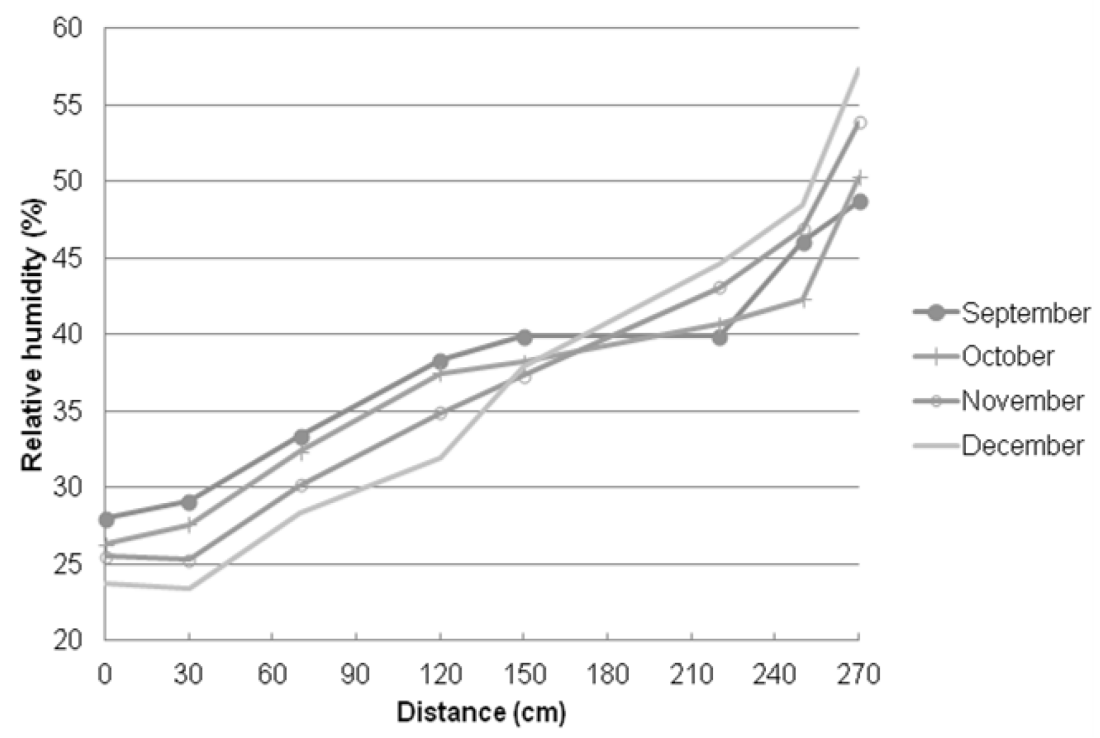

Figure 7: Relative humidity measured during the autumn and winter of 2012.

The data in Figures 4-7 represent temperature and relative humidity values measured for the $15^{\text {th }}$ day of the particular months. The measured temperature 
values gave information on the thermal performance of the monitored wall. During the spring, autumn and winter, the interior surface temperature was more or less constant, about $21.5^{\circ} \mathrm{C}$. This value is comfortable from the point of view of quality of interior climate for building users, especially taking into account administrative character of the tested building. On the other hand, in the summer period of the year, the interior surface temperature increased even up to $26^{\circ} \mathrm{C}$. This temperature increase has negative effect on building users comfort and should be solved for example by air conditioning or reconstruction of building envelope. The interior relative humidity was mostly low. However, this does not represent any substantial risk of decrease of the comfort quality for the users.

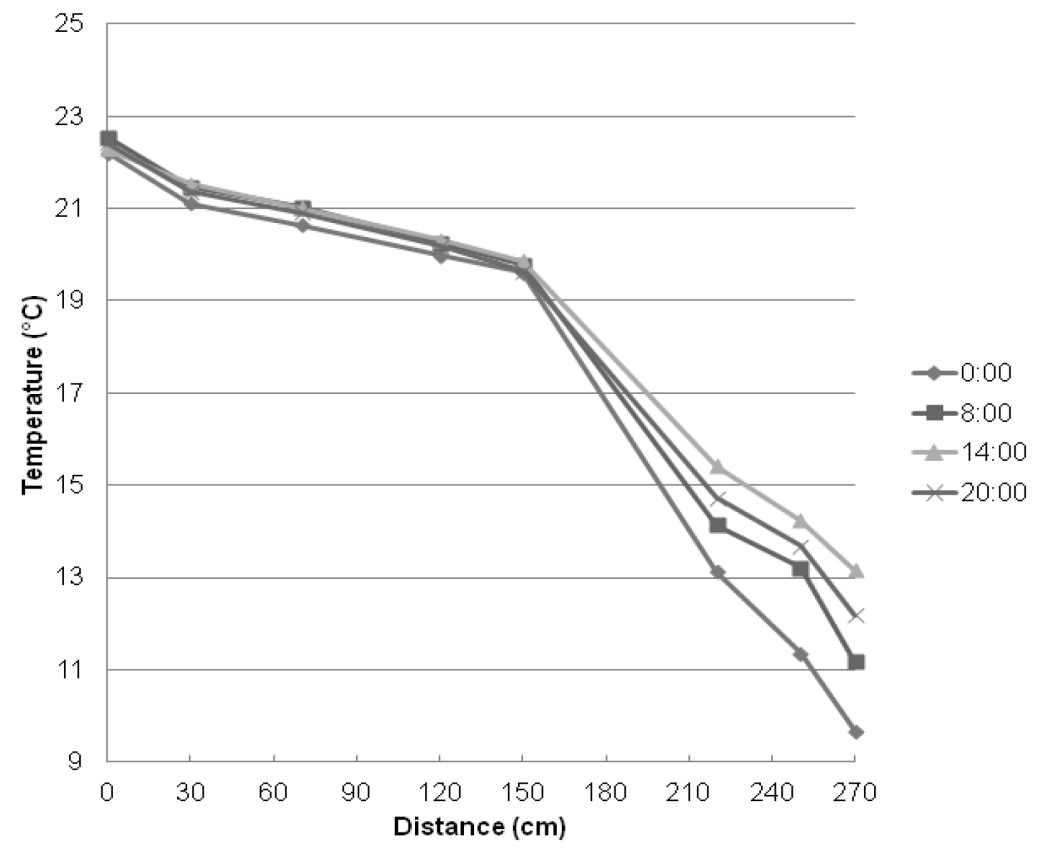

Figure 8: Daytime variation of temperature profiles.

In Figures 8 and 9, there are presented temperature and relative humidity daytime variations corresponding to November 30, 2012. We can observe noticeable changes of temperature values measured in the exterior part of the tested wall during the day and night. On the other hand, the differences in relative humidity profiles are practically negligible. 


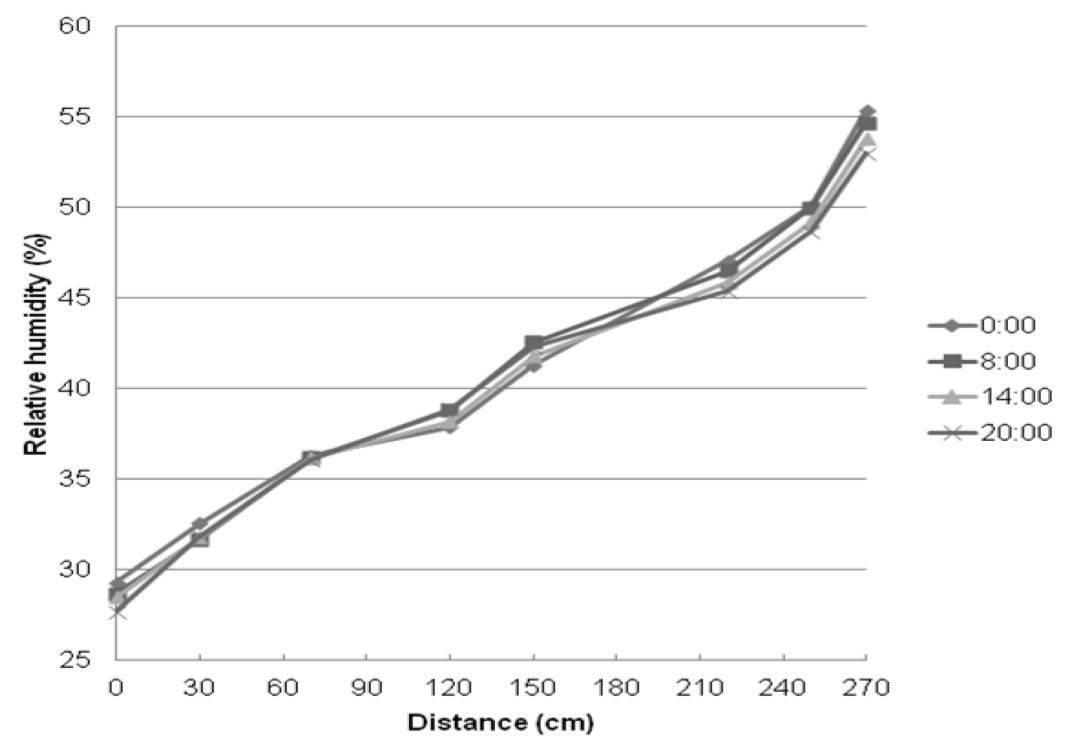

Figure 9: Daytime variation of relative humidity profiles.

\section{Conclusions}

Experimental results presented in this paper gave information on hygrothermal performance of the studied building envelope. Within the initial part of the monitoring process that started in 2012, the proposed in-situ monitoring system proved its applicability. Therefore, it will be used also in future years for longtime analysis of researched building.

Looking at the obtained data, two important features were identified. Firstly, in the summer period of the year, the interior temperature noticeably increased and had negative impact on the interior climate from the point of view of building users comfort. Secondly, the temperature differences between exterior and interior surface of the wall were typically balanced in $150 \mathrm{~mm}$ of the envelope. Although this finding can be generally considered as good in light of thermal insulation function of the tested structure, application of more sophisticated exterior thermal insulation system should be entertained.

In future work, the measured data will be analysed by computational modelling methods taking into account the mechanical damage model describing the stress and strain of inbuilt materials in dependence on temperature and moisture changes. This will allow long-time simulation of building performance as well as identification of possible degradation processes.

\section{Acknowledgement}

This research has been supported by the Czech Science Foundation, under project No P105/12/G059. 


\section{References}

[1] Pavlík, Z., Michálek, P., Pavlíková, M., Kopecká, I., Maxová, I., Černý, R., Water and Salt Transport and Storage Properties of Mšené Sandstone. Construction and Building Materials, 22(8), pp. 1736-1748, 2008.

[2] Jiřičková, M., Pavlík, Z., Fiala, L., Černý, R., Thermal Conductivity of Mineral Wool Materials Partially Saturated by Water. International Journal of Thermophysics, 27(4), pp. 1214-1227, 2006.

[3] Pavlík, Z. and Černý, R., Experimental assessment of hygrothermal performance of an interior thermal insulation system using a laboratory technique simulating on-site conditions. Energy and Buildings, 40, pp. 673678, 2008.

[4] Pavlík, Z, Jiřičková, M., Černý, R., Sobczuk, H., Suchorab, Z., Determination of moisture diffusivity using the time domain reflectometry (TDR) method. Journal of Building Physics, 30(1), pp. 59-57, 2006.

[5] Pavlík, Z., Jiřičková, M., Pavlík, J., Černý, R., Interior thermal insulation system based on hydrophillic mineral wool. Journal of Building Physics, 29(1), pp. 21-35, 2005.

[6] Garcia Tremps, A. and Mora, D., Energy performance assessment of building systems with computer dynamic simulation and monitoring in a laboratory. Energy and Sustainability III Book Series: WIT Transactions on Ecology and the Environment, 143, pp. 449-460, 2011.

[7] Kijewski-Correa, T., Kochly, M., Monitoring the wind-induced response of tall buildings: GPS performance and the issue of multipath effects, Journal of Wind Engineering and Industrial Aerodynamics, 95, pp. 1176-1198, 2008.

[8] Bashor, R., Bobby, S., Kijewski-Correa, T., Kareem, A., Full-scale performance evaluation of tall buildings under wind. Journal of Wind Engineering and Industrial Aerodynamics, 101-106, pp. 88-97, 2012.

[9] Omenzetter, P., Morris, H., Worth, M., Kohli, V., Uma, S. R., Long-term monitoring and field testing of an innovative multistory timber building. Nondestructive Characterization for Composite Materials, Aerospace Engineering, Civil Infrastructure, and Homeland Security 2011, Book Series: Proceedings of SPIE, 7983, 2011.

[10] Brunner, S. and Simmler, H., In situ performance assessment of vacuum insulation panels in a flat roof construction. Vacuum, 82, pp. 700-707, 2008.

[11] Janssens, J. and Hens, H., Effect of wind on the transition heat loss in duopitched insulated roofs: A field study. Energy and Buildings, 39, pp. 10471054, 2007.

[12] Swinton, M. S., Maref, W., Bomberg, M. T., Kumaran, M. K., Normandin, N., In situ performance evaluation of spray polyurethane foam in the exterior insulation basement system. Building and Environment, 41, p. $1872-80,2006$. 